\title{
Mirror, mirror on the screen, what does all this ASCII mean?: A pilot study of spontaneous facial mirroring of emoticons
}

\author{
Brittney O’Neill
}

\begin{abstract}
Though an ever-increasing mode of communication, computer-mediated communication (CMC) faces challenges in its lack of paralinguistic cues, such as vocal tone and facial expression. Researchers suggest that emoticons fill the gap left by facial expression (Rezabek \& Cochenour, 1998; Thompson \& Foulger, 1996). The fMRI research of Yuasa, Saito, and Mukawa (2011b), in contrast, finds that viewing ASCII (American Standard Code for Information Interchange) emoticons (e.g., :), :( ) does not activate the same parts of the brain as does viewing facial expressions. In the current study, an online survey was conducted to investigate the effects of emoticons on perception of ambiguous sentences and users' beliefs about the effects of and reasons for emoticon use. In the second stage of the study, eleven undergraduate students participated in an experiment to reveal facial mimicry responses to both faces and emoticons. Overall, the students produced more smiling than frowning gestures. Emoticons were found to elicit facial mimicry to a somewhat lesser degree than photographs of faces, while male and female participants differed in response to both ASCII emoticons and distractor images (photos of non-human, non-facial subjects used to prevent participants from immediately grasping the specific goal of the study). This pilot study suggests that emoticons, though not analogous to faces, affect viewers in ways similar to facial expression whilst also triggering other unique effects.
\end{abstract}

Key Terms: emoticons; computer-mediated communication (CMC); facial mimicry; paralinguistic cues; gender; interaction; facial expression; facial action coding system (FACS); internet

\section{Introduction}

As reliance upon computer-mediated communication (CMC) - whether instant messaging, texting, email, or even Facebook - increases, it is becoming more important to understand how both language and paralanguage function in this new medium. The current study explores the 
role of emoticons as paralinguistic markers, specifically insofar as they perform the role of facial expression in face-to-face (FTF) communication.

During the rise of the Internet in the early 1980s, Internet users encountered difficulty conveying emotion, namely humour, in rapid, casual, textual interaction. As a solution to the problem, Scott Fahlman, a computer scientist at Carnegie Mellon, proposed the first two emoticons:

19-Sep-82 11:44 Scott E. Fahlman :-)

From: Scott E. Fahlman <Fahlman at Cmu-20c>

I propose that the following character sequence for joke markers:

:-)

Read it sideways. Actually, it is probably more economical to mark things that are NOT jokes, given current trends. For this, use :-( (Fahlman, 1982)

Emoticons have since become ubiquitous in CMC and are often assumed to be textual representations of the non-verbal cues displayed through facial expressions (Danet, Ruedenberg-Wright, \& Rosenbaum-Tamari, 1997; Thompson \& Foulger, 1996). In spite of this view, Dresner and Herring (2010) suggest in passing that emoticons do not behave exactly as do facial expressions, namely that viewers of emoticons do not mirror the emoticon expression as they would mirror a genuine facial expression.

The current study addresses emoticons' potential to trigger spontaneous facial mimicry (a viewer's spontaneous recreation of facial muscular patterns observed in another face). Ultimately, this research strives to enrich our understanding of how emoticons impact the experience of CMC as a social and emotional environment through behavioural rather than textual investigation.

\section{Literature Review}

The relationship between an emoticon or "emotional icon" and its corresponding facial expression has regularly been taken for granted. Rezabek and Cochenour (1998), for example, assume that emoticons are "visual cues formed from ordinary typographical symbols that when read sideways represent feelings or emotions" (p. 201), likewise, Thompson and Foulger (1996) state that emoticons are used "to express emotion or as surrogates for nonverbal communication" (p. 226). These implicationsthat emoticons are representative of emotions and are used as surrogates for nonverbal communication-suggest that they are viewed as textual replacements for emotionally expressive nonverbal cues, namely facial expression. 
Even those researchers who have sought to explain emoticons as other than replacements for facial expression (Garrison, Remly, Thomas, \& Wierszewski, 2011; Lo, 2008; Dresner \& Herring, 2010) have conceded that at least some aspect of the role of emoticons is textual representation of facial expression. Dresner and Herring (2010) allow that emoticons, to at least some degree, act as textual surrogates for facial expressions (FTF). Similarly, Garrison et al.'s (2011) study of emoticon distribution concludes that emoticons are conventionalized paralinguistic markers - rather like facial expressions. Thus, though many researchers have simply assumed that emoticons are analogous to facial expressions (Danet et al., 1997; Rezabek \& Cochenour, 1998), those who have questioned the assumption ultimately concede that emoticons seem to be, to at least some extent, analogous to facial expressions. These conclusions, however, rely on textual analysis and fail to provide behavioural evidence from emoticon users.

\section{Emoticons in Use}

Studies have also worked to explore how emoticons are used and when they appear (Baron, 2004; Garrison et al., 2011). Researchers (Wolf, 2000; Baron, 2004) have found that women typically use more emoticons than men. Wolf (2000) suggests that this usage pattern may be related to the supportive and empathetic nature of female communication in the newsgroups studied, but it may also be attributable to women's increased expressiveness in both CMC and FTF. Buck, Savin, Miller, and Caul (1972) found that women are more facially expressive than men in FTF. Thus, if emoticons are replacing facial expression in CMC, women's increased use of emoticons may follow from their increased facial expressiveness in FTF. This gender difference, as suggested by the nature of the newsgroups involved, may also be a feature of women's greater empathy responses when viewing emotive facial expression as compared to men (Ruekert \& Naybar, 2008). The data collected regarding women's emoticon use, however natural, was not experimental and failed to isolate emoticons from other contexts such as the newsgroup topic and membership.

It is also noteworthy that emoticons seem to act as punctuation. Both Provine, Spencer, and Mandell (2007) and Garrison et al. (2011) found that emoticons generally occur at either utterance, sentence, or phrase breaks. Provine et al. (2007) analyse this trend in light of existing knowledge of laughter distribution in speech and signing conversations. They conclude that, laughter appearing as it does — only at natural breaks between statements or ideas, both in speech (where there is a mechanical conflict) 
and in signing (where communication and laughing could be simultaneous) — must be evidence for a separate level of non-verbal emotion processing which is subordinate to verbal processes. The similar patterning of emoticons then suggests that they, like laughter, are a product of this secondary emotional pathway, rather than of the textual verbal stream.

Derks et al. (2008a) also surveyed subjects' motivation for use. They found that "emoticons are mostly used to express emotion, to strengthen a message, and to express humor" (p. 99). Similarly, facial expression intuitively performs the same work and can be volitionally displayed, as are emoticons; however, the existing research is limited by a lack of behavioural evidence, relying instead upon self reporting from participants.

Emoticons also improve the CMC experience for a range of users, both professionals and undergraduate students (e.g. Huang, Yen, \& Zhang, 2008; Rivera, Cooke, \& Bauhs, 1996). Just as facial expressions lead to emotional contagion - sympathetic experience of an emotion when interacting with an individual experiencing the emotion (Wild, Erbs, \& Bartels, 2000) - use of emoticons increased participants' "enjoyment, personal interaction, perceived information richness, and perceived usefulness" (Huang, et al., 2008, p. 466). Users have also reported that CMC interfaces that provide easy access to emoticons are more satisfactory and effective than those that do not (Rivera et al., 1996). Such findings point to a valuable, face-like role for emoticons in facilitating comfortable and natural interaction through $\mathrm{CMC}$, thus begging for further exploration beyond the self-reporting paradigm.

\section{Perception of Emoticons}

$\mathrm{CMC}$ researchers have also sought to understand the impact emoticons have on recipients. If emoticons are analogous to facial expression in distribution and effect upon producers, then they ought to be analogous to facial expressions in perception as well.

In Walther and D'Addario's (2001) early study on emoticons and sentence valence, positive or negative phrases were embedded into an email along with either :), ; ) : ( , or nothing. Participants were then asked to judge the valence of the message on a number of criteria, such as happiness, sarcasm, and positivity. Emoticons did not change the valence of a statement, but any samples with a negative component (text or emoticon) were rated significantly more negative than either neutral or positive statements without a negative component. Though Walther and D'Addario (2001) took this finding as evidence that emoticons are not analogous to 
facial expression, the sentences used were perhaps too absolute to be affected by any nonverbal input, hence the lack of effect on participant ratings.

Further studies, which added neutral conditions to the paradigm, found much stronger evidence of emoticon effect upon message interpretation (e.g. Lo, 2008; Luor, Wu, Lu, \& Tao, 2010). Closely following Walther \& D'Addario (2001)'s methodology, Derks, Bos, and Grumbkow (2008b), for example, found that emoticons can enhance a verbal message. In mixed message conditions, they also found that, though emoticons do not invert the valence of the verbal phrase, adding a conflicting emoticon leads to greater ambiguity and reduces the positivity or negativity of the statement when compared to the same sample without an emoticon. This suggests that though emoticons may not have the same power over message interpretation as facial expression, they still have a self-reported impact on message recipients and can be used to moderate valence. It remains then to see if this conscious effect is replicated in more unconscious behavioural measures, such as facial and neural response.

Yuasa, Saito, and Mukawa (2011b) address the question of neural response. They used fMRI to localize the neural activity of subjects viewing verbal statements accompanied by sentence final textual emoticons. The results of the fMRI showed that subjects' brains were activated in the area associated with emotional discrimination but were not in either the area responsible for processing emotional words, or the area activated by viewing faces. This study, however, used Japanese style emoticons (e.g. ^_^; T_T), which focus on eye, rather than mouth, shape, as do Western emoticons. Thus, these results require further exploration with the contrasting Western emoticons (e.g. :) ; :( ) and within the cultural context of Western internet users.

Later work by Yuasa, Saito, and Mukawa (2011) showed that graphic emoticons, which are not limited by the conventions of ASCII (American Standard Code for Information Interchange) and bear stronger resemblance to faces, activate the area used in emotional discrimination, as well as the area active when viewing faces, though to a lesser degree than actual faces. On the basis of this neuropsychological evidence, it is reasonable to suggest that further research may show that emoticons and other graphic representations of faces occur on a continuum of similarity to faces, and are active in triggering emotional judgements in ways akin to other nonverbal cues. 
In a related field, Chaminade et al. (2010) found that subjects show greater visual activity and motor resonance (brain activation in motor areas associated with the actions being performed by another) when viewing a humanoid robot forming facial expressions than when viewing a human doing the same. Such resonance is connected to feelings of connectedness in human-to-human interaction. Thus, Chaminade et al. (2010) state that their findings suggest that exposure to non-human facial expressions may provide similar benefits of improved social well being, physical health, and emotional wellness, as does exposure to human facial expression. Emoticons then may, like the study's robot, be able to act as wellness enhancing surrogates for FTF facial expression if they are shown to provide similar emotional and social effects.

\section{Facial Mimicry}

Research using electromyographic (EMG) information has established that viewing emotional facial expressions causes subjects' facial muscles to activate in a pattern similar to that found in the emotional expression presented (e.g. Cacioppo \& Petty, 1981; Dimberg \& Lundquist, 1990; Dimberg, Thunberg, \& Elmehed, 2000). Sato and Yoshikawa (2007) also found these effects are sufficiently large enough to be captured by the naked eye, without the assistance of EMG. This behaviour, called "facial mimicry" (Hess, Philippot, \& Blairy, 1999), is related to Hatfield, Cacioppo, and Rapson's (1994) rendering of emotional contagion, in the experience of sympathetic emotion through the adoption of another's posture, tone, expression, and movement. Thus, humans are able to communicate emotion by non-verbal behaviour alone.

Similarly, as discussed above (see Derks et al., 2008b), emoticons can impact the interpretation of the valence of messages. This has been assumed to be related to the role of emoticons as textual facial expressions (e.g. Derks et al. 2008b, Luor et al., 2010). Therefore, their impact upon recipients may be an effect of emotional contagion and may be accompanied by facial mimicry.

\section{Research Questions and Hypotheses}

Building upon existing research in emoticon perception and response, this project seeks to understand whether and to what degree viewers will mimic the emotional expressions of emoticons vis-à-vis faces. If emoticons are assumed to be representations of facial expression and to act in ways akin to facial expression, the fact that exposure to facial expressions instigates 
facial mimicry suggests that emoticons ought to instigate a facial mimicry as well. Thus, the current study first explores to what degree, if at all, emoticons will elicit facial mimicry in viewers.

Because women are both heavier users of emoticons (Baron, 2004) and more susceptible to emotional contagion (Doherty, Orimoto, Singelis, Hatfield, \& Hebb, 1995), women are predicted to show more facial mimicry than do men. Therefore the second question addressed in this research is whether or not there is an appreciable gender difference in the facial mimicry responses of male and female participants.

\section{Online Survey}

Methodology

In the first part of this study an Internet-based survey was administered using the online survey service Inqwise. The survey displayed neutral utterances (such as, "Today is so hot") with embedded emoticons and asked respondents to report their perceptions of and reaction to the sample. Responses were recorded on five-point Likert scales for positivity of the statement, perceived happiness of the writer, and effect on the reader's emotional state. Following a sequence of nine samples, three with :), three with :(, and three with no emoticon, participants were asked general questions about their reactions to emoticons, such as "When you read statements followed by :) did your facial expression change?" and "Do you think that emoticons affect your interpretation of messages?" The survey was distributed through two linguistics related Facebook groups based out of a Western Canadian university. The survey was designed to provide a backdrop for the experiment by exploring the self-reported experiences of Internet users, specifically those engaged with linguistic groups on Facebook.

\section{Results}

The survey initially returned twenty-three respondents. Due to a technical issue, date of birth was not recorded for any of the participants. One participant, however, reported having been in Canada for over thirty years - thus falling outside of the 18-30 year old demographic - and was removed. Two further participants were removed as they seemed to have misinterpreted the Likert scale for happiness of writer on most or all of the samples. Responses for happiness of writer were removed from other participants' data if and only if they were in direct opposition to the participant's ratings for both positivity of statement and effect on reader's 
mood. After data cleaning, twenty respondents remained, three of whom had two responses removed and one of whom had three removed.

Seventeen of the remaining twenty respondents were female. As a result, the question of gendered response to emoticons could not be addressed in this segment of the study.

Throughout the survey, emoticons were reported to affect the interpretation of messages and were seen to be indicators of the writer's emotion. Effects on the reader's mood or self reported internal emotional valence, however, varied far more widely across individuals. All respondents indicated that they believed that emoticons affect interpretation of online statements, but only $10 \%$ of respondents believed that their facial expression was affected by the :( emoticon, and only $20 \%$ believed that their facial expression changed in response to viewing the :) emoticon.

The ratings for positivity of sentence and happiness of writer generally corresponded with the findings of Lo (2008) and Luor et al. (2010). They showed emoticons affecting and to some extent dictating the interpretation of ambiguous messages. For messages followed by :), the average positivity rating was 4.52 on a 5 point Likert scale, where 5 was positive and 1 was negative. Contrastively, statements followed by :( received a low rating for positivity (1.63 on the same 5 point Likert). Finally, statements lacking emoticons received an average rating of 2.97 , which is nearly neutral on the 5-point scale. Figure 1 shows the range of responses for each stimulus. These results suggest that the addition of an emoticon was sufficient to provide a strongly positive or negative reading of otherwise neutral statements.

\section{•)}
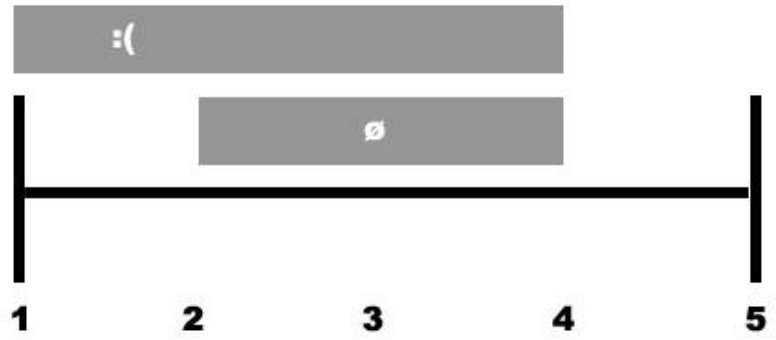

Figure 1. Response distribution for Statement Positivity. Note: $1=$ Negative; $5=$ Positive. 
Location of the white icon indicates the average rating.

In terms of writer happiness, as shown in Figure 2, a similar, if more dispersed pattern was found. Sentences followed by :) were, on average, rated as 1.71 on a 5-point Likert Scale where 1 is happy and 5 is unhappy, whereas sentences followed by : ( had an average rating of 4.15 and sentences without an emoticon received an average rating of 2.93. Again, the verbal content of the message conveys little about the writer's mood, but an emoticon can shift judgements significantly in both positive and negative directions.

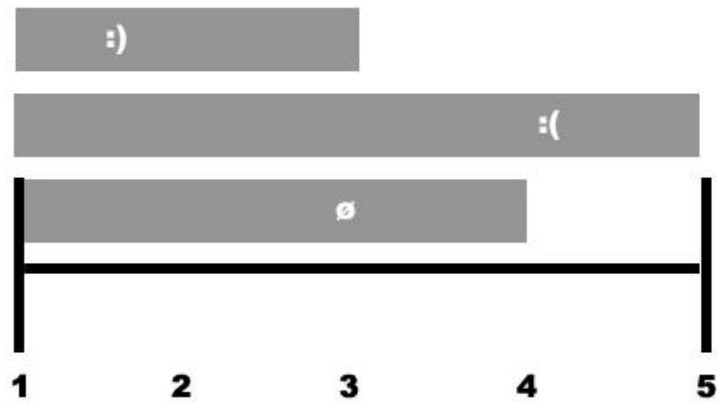

Figure 2. Response distribution for Writer Happiness.

Note: 1 = Happy; 5 = Unhappy.

Location of the white icon indicates the average rating.

Reader's mood however, was less consistently affected. Where positivity generally had a spread of only two to three points, effect on the reader's mood had much wider distributions, as shown in Figure 3, and less valenced average responses. For sentences followed by :), reader's mood ranged from 2 to 5, with an average of 3.63 on a 5-point Likert scale where 1 corresponds to negative effects and 5 to positive effects. Sentences with the :( emoticon saw responses range from 1 to 5, with an average response of 2.65. Sentences without emoticons also had a wide range of response from 1 to 4, with an average of 2.87. Though emoticons may be able to shift the reader's mood somewhat in the direction of the emoticon, it is neither a strong nor consistent effect. 


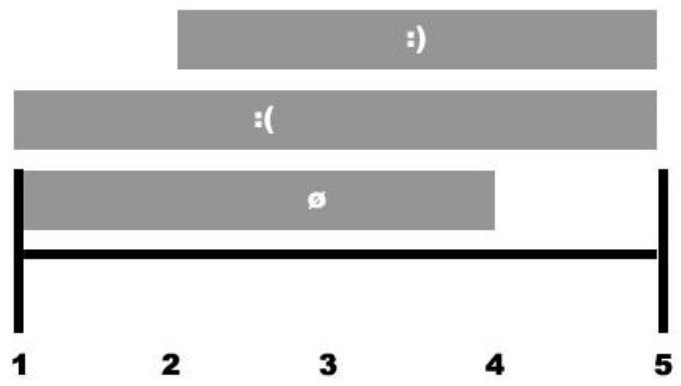

Figure 3. Response distribution for Effect on Reader's Mood. Note: 1 = Negative; 5 = Positive.

Location of the white icon indicates the average rating.

The results found through rating sentences were confirmed by responses to the general questions on the final page of the survey. All twenty participants agreed that emoticons affect the interpretation of messages, many commenting that emoticons show the writer's mood or intent. Only four of twenty participants, however, believed that their facial expression was affected by viewing :), and fewer still, only two, believed that :( affected their facial expression. This suggests that, just as participants experienced mild, inconsistent effects on mood when viewing emoticons, they do not believe that the physical manifestation of their mood is affected by emoticons. Self-reporting is not, however, always accurate, and so the in-lab experimental portion of this research was carried out to further explore the actual facial responses of participants.

\section{Mirroring Experiment}

\section{Methodology}

Following the established methodology of facial mimicry experiments (Dimberg \& Lundquist, 1990; Sato \& Yoshikawa, 2007), the second part of this study presented participants with a range of photographs of emotional faces, both the :) and :( emoticons, and non-human, non-facial distractor images. Participants were filmed watching the pre-timed slideshow. Their facial responses were then hand coded for expression indicators at the mouth and the brows. 


\section{$\underline{\text { Participants }}$}

Five female and six male Canadian undergraduate students ranging in age from 18-26 participated. All participants had spent at least 18 years living in Canada. All also reported owning their own computer and cellphone, and had an Internet connection in their residence. Only one female owned a smartphone, while all but one of the males reported owning one. All participants reported using the Internet and texting to communicate at least once a day, and all but one participant reported regularly sending and receiving emoticons. Thus it can be assumed that all participants were fully computer and texting literate and had regular exposure to emoticons as a part of their CMC.

\section{Materials}

This study was conducted using an iMac computer in the University of Victoria Phonetics Lab. The computer was equipped with Microsoft Powerpoint, which ran a pre-timed slideshow of stimuli. The stimuli themselves were eight images - two males and two females each producing a smile and a frown - from the Max Planck Institute's FACES Database (Ebner, Riediger, \& Lindenberger, 2010); the :) and :( emoticons (each repeated four times); four strings of nonsense ASCII characters; and four distractor photos (a boat, a bird, a palm tree, and a bridge sourced from freemediagoo.com). While viewing these stimuli, participants were recorded using a Panasonic Lumix DMC-FP1 camera with a frame rate of 30 frames per second. The camera was mounted on a tripod at the upper left corner of the iMac screen.

\section{Procedure}

It was made clear to participants that they were being filmed, but the purpose of filming was not clearly disclosed so as to prevent interference. Participants were then seated before the computer screen and instructed to watch a fixation point.

In terms of trial set-up, this study largely follows Dimberg and Lundquist (1990), with some timing factors adjusted. Dimberg and Lundquist used a stimulus interval of 8 seconds (s) and an inter stimulus interval of 20-40s, but found that reactions occurred within the first 500 milliseconds (ms). Thus, in order to reduce the potential for participant boredom in the current study, each stimulus appeared for $5 \mathrm{~s}$ with an interstimuli interval of $10 \mathrm{~s}$ wherein the fixation screen was presented (see figure 4 for an example trial). Stimuli occurred in a random order and each 
participant performed two blocks of six minutes each. Each block contained all of the 24 stimuli, and the participant had an optional break between blocks.

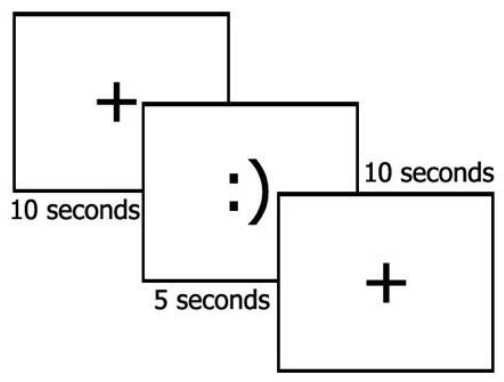

Figure 4. Procedure

Upon completion of the two blocks, participants were then given a brief demographic survey to ascertain their age, gender, and level of exposure to emoticons.

\section{$\underline{\text { Analysis }}$}

Because of the small size of the sample, statistical models were not used. Facial responses were hand coded following Sato and Yoshikawa's (2007) use of Ekman and Friesen's (1978) FACS (facial action coding system), which uses anatomical changes to code human facial movement without any gross interpretation of emotion from coders. Specifically, participant's faces were coded for visible occurrences of brow tension, facial action unit (AU) 4, prototypical of negative expressions, and lip pulling or zygomatic tension, AU 12, typical of smiles (see figures 5 and 6 for an example).

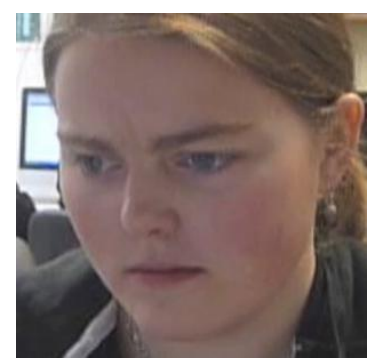

Figure 5. AU 4 - Brow

Lowering (Author's image)

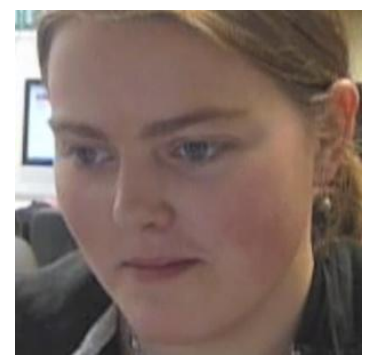

Figure 6. AU 12 - Lip Pulling (Zygomatic tension) (Author's image) 
After the participants' video files were coded for occurrence of these facial AUs, the time of occurrence for each AU was associated with the chronology of stimulus presentation. During the course of this association, it was found that some participants, specifically males, seemed to have response latencies such that the facial change occurred during the fixation screen following the stimulus. As a consequence, any AU occurring within the first five seconds of a fixation screen was associated, in the analysis, to the stimulus immediately preceding it. A further complication arose with one participant who commonly and prominently used a brow raise as a response to stimuli. Given that the action was generally accompanied by AU 12, it was assumed to also be a positive facial indicator and was coded as such.

After samples were coded and associated to stimuli, rates of positive (AU 12) and negative (AU 4) reaction were calculated for groups of stimuli both within and across genders. These rates of response were compared, as were raw scores for numbers of responses in a range of categories.

\section{Results}

Though as many negative as positive stimuli were presented, participants produced considerably more positive than negative facial cues. Out of a total of 166 AUs produced by the participants, only 21 were negative. Furthermore, though males' expressions were less intense and less obvious, they were found to be more frequent than females', with male participants producing an average of 16.17 gestures per participant, while females only produced an average of 13.8 per participant. In contrast with the other three females, the two female participants between the ages of 18 and 20 only exhibited four and six responses respectively. Compared with the 18-20 year old male's 24 responses, this behaviour seems anomalous, especially given that women were expected to produce more mirroring (see Doherty et al., 1995). To remove these results, however, reduces the female sample size to only three participants. Furthermore, the unresponsive females may be representative of a specific age-based behaviour, and so their data was not discarded. In the following findings, all participants' data is retained.

\section{$\underline{\text { Response to Faces }}$}

Previous research (Cacioppo \& Petty, 1981; Dimberg \& Lundquist, 1990; Dimberg et al., 2000) has set a precedent of facial mimicry to photographs of faces, but this study found some unexpected patterns. Participants were minimally more responsive to angry faces than to happy ones (38 responses 
versus 35 responses), and most of these responses, 36 and 33, respectively, were positive.

Though consistently following the same overall ratios of reaction, men and women differed in the specific frequency of reaction to facial stimuli. Women responded to photographs of faces $36.25 \%$ of the time, whereas men responded to $46.87 \%$ of faces. Within each stimulus type, the same pattern appears, with men responding 10-13\% more frequently than women (see Table 1 details). Overall, participants responded $41.5 \%$ of the time for emotional faces (43.18\% for angry and $39.77 \%$ for happy).

\section{Table 1}

Response rates for facial action units in response to photographs of faces

\begin{tabular}{llll}
\hline Stimulus & Participant & & $\begin{array}{l}\text { Rate of } \\
\text { Reaction }\end{array}$ \\
\hline Smile & Female & & $32.50 \%$ \\
& Male & Total: & $45.83 \%$ \\
& & & $\mathbf{3 9 . 7 7 \%}$ \\
Frown & Female & & $37.50 \%$ \\
& Male & \multirow{2}{*}{ Total: } & $47.92 \%$ \\
& & & $\mathbf{4 3 . 1 8 \%}$ \\
Total & Female & & $36.25 \%$ \\
& Male & \multirow{2}{*}{ Total: } & $46.87 \%$ \\
& & & $\mathbf{4 1 . 5 0 \%}$ \\
\hline
\end{tabular}

\section{$\underline{\text { Response to Emoticons }}$}

Like the responses to emotional facial expressions, the responses to emoticons were predominantly positive, with only two negative responses to :( and none for :). Responses to emoticons did, however, have a much lower overall response rate, at only $26.63 \%$, than did faces (see Table 2 for response rate breakdown by emoticon type).

Table 2

Response rates for facial action units in response to emoticons

\begin{tabular}{|c|c|c|}
\hline Stimulus & Participant & $\begin{array}{l}\text { Rate of } \\
\text { Reaction }\end{array}$ \\
\hline \multirow[t]{3}{*}{ :) } & Female & $32.50 \%$ \\
\hline & Male & $22.92 \%$ \\
\hline & Total: & $27.27 \%$ \\
\hline
\end{tabular}




\begin{tabular}{llll}
\hline $\mathbf{:}($ & Female & & $13.33 \%$ \\
& Male & & $36.11 \%$ \\
\multirow{3}{*}{ Total } & & Total: & $\mathbf{2 5 . 7 6 \%}$ \\
& Female & & $22.86 \%$ \\
& Male & & $28.57 \%$ \\
& & Total: & $\mathbf{2 6 . 6 2 \%}$ \\
\hline
\end{tabular}

Responses to emoticons also showed clear gender differences in patterns of responsiveness. Women seem to be more responsive to :) than :(, where men exhibit greater responsiveness to :( than to :) and less of a difference in response overall. As seen in Table 2, women respond to :) at a rate of $32.50 \%$ and to :( at a rate of only $13.33 \%$. In contrast, men respond to :( $33.33 \%$ of the time, but to :) only $22.92 \%$ of the time.

\section{$\underline{\text { Response to Distractors }}$}

Though designed only to prevent participants from immediately discovering the purpose of the study, the distractor stimuli yielded interesting patterns of response. Participants responded to photographic distractors $23.86 \%$ of the time, only slightly less than they responded to emoticons (26.63\%). This response rate may however be an effect of a single distractor: the seagull. The seagull had a response rate of $36.36 \%$, and several participants, after the experiment, mentioned that they had liked the seagull, or had laughed at it as a result of personal experience with seagulls. Without the seagull, the average response to distractors drops to $19.70 \%$.

Table 3

Response rates for facial action units in response to photographic distractors

\begin{tabular}{llll}
\hline Distractors & Participant & & $\begin{array}{l}\text { Rate of } \\
\text { Reaction }\end{array}$ \\
& & & $25.00 \%$ \\
All Photos & Female & & $22.92 \%$ \\
& Male & \multirow{2}{*}{ Total: } & $\mathbf{2 3 . 8 6 \%}$ \\
\multirow{2}{*}{ Seagull } & Female & & $30.00 \%$ \\
& Male & & $41.67 \%$ \\
& & Total: & $\mathbf{3 6 . 3 6 \%}$ \\
All Photos & Female & & $23.33 \%$ \\
- seagull & Male & & $16.67 \%$ \\
& & Total: & $\mathbf{1 9 . 7 0 \%}$ \\
\hline
\end{tabular}


Beyond the responses to the photographic distractors, participants also responded unexpectedly frequently to the ASCII distractors. In fact, at a response rate of $29.55 \%$, ASCII strings provoked more reaction than did emoticons. Furthermore, as shown in Table 4, these distractors show an even more dramatic gender difference than did emoticons. Firstly, women respond more in general to the ASCII strings, but they respond primarily negatively, responding with brow lowering $27.5 \%$ of the time and with mouth pulling only $5 \%$ of the time. In contrast, men exhibit positive facial cues $22.92 \%$ of the time and negative cues only $4.17 \%$ of the time.

Table 4

Response rates for valenced facial action units in response to ASCII strings

\begin{tabular}{llll}
\hline Distractors & Participant & Response & Rate of \\
& & Valence & Reaction \\
\hline ASCII & Female & Positive & $5.00 \%$ \\
& Negative & $27.50 \%$ \\
& \multirow{2}{*}{ Total: } & $\mathbf{3 2 . 5 0 \%}$ \\
& \multirow{2}{*}{ Male } & Positive & $22.92 \%$ \\
& Negative & $4.17 \%$ \\
& \multirow{2}{*}{ Total: } & Positive & $\mathbf{2 7 . 0 9 \%}$ \\
& Negative & $14.77 \%$ \\
& \multicolumn{2}{c}{ Total: } \\
\end{tabular}

\section{Discussion}

As well as finding evidence of mirroring for both faces and emoticons, the current study found that participants produced more positive than negative facial cues to all facial stimuli, even negative ones. This is unexpected, as other studies (Sato \& Yoshikawa, 2007; Dimberg \& Lundquist, 1990) have found that participants produce facial AUs that correspond in valence to the stimulus at hand. Our results may, however, be explained by the participants' unsolicited reporting that some of the angry faces were "funny looking" or "made them laugh." This reaction may be the result of placing participants in the unnatural position of watching facial expressions of unknown individuals in a low-context environment. Without context, the faces may lose their emotional power, or be seen as misplaced. Thus, they elicit nervous smiles rather than sympathetic frowns. Similarly, in the 
survey segment of the study, some participants complained about the inappropriateness of an emoticon that shifted sentences to a valence that they disagreed with or found implausible. Thus, facial expression or emoticons alone do not necessarily elicit an emotion, but instead require context to have a full effect upon the viewer.

The difference in rates of response seen between emoticons and faces also suggests that the two, though playing similar roles in eliciting response, are not entirely equivalent. The presence of additional gender differences with emoticons, but not with faces, also seems to suggest that emoticons trigger a different and more gender specific emotional response than do faces.

\section{"Faceness" and emotional contagion}

Given the large discrepancy between facial mimicry triggered by expressive faces versus emoticons, it is clear that, in terms of facial mirroring, emoticons are not analogous to faces. This may, however, correspond to Yuasa, Saito, and Mukawa's (2011a) findings that viewing graphic emoticons causes activation of the facial perception regions of the brain, albeit to lesser a degree than do actual faces. As previously mentioned, this may suggest that there may be a continuum of 'face-ness' (or face likeness), ranging from things which are not at all like faces and do not activate the facial perception region at all, through graphic representations of faces that activate the region to a small degree, to actual human faces which activate the area fully. On this model, ASCII emoticons are further down on the continuum than graphic emoticons. While the ASCII forms do not seem to trigger measurable activation in the face perception regions (Yuasa et al., 2011a), they do trigger some facial mimicry. Thus, since facial mimicry is associated uniquely with faces, ASCII emoticons' instigation of facial mimicry suggests that the brain sees them as faces, if not necessarily triggering the same degree of neural activation as actual faces.

Another potential explanation for the differences in mimicry may be available in further consideration of the relation between emotional contagion and facial mimicry. If facial mimicry is a result of emotional contagion, since it was found in the survey that viewing emoticons does in fact influence mood to some extent, then the emoticons may be relying on that influence on mood, rather than any relative 'face-ness', to create emotional contagion which leads to facial mimicry. Actual human faces, however, being both high on the scale of face-ness and triggering emotional 
contagion naturally, result in more consistent facial mimicry than do emoticons.

This sort of understanding of face-ness, facial mimicry, and emotional contagion, not only help enhance the average internet user's experience of CMC, but may also help to better understand conditions such as Autism Spectrum Disorder, which may involve difficulties understanding and communicating paralinguistic information such as facial emotional cues (Hobson, 1988). For those experiencing disorders along this spectrum, :) might be just as information rich as an actual human smile.

\section{Gender issues in ASCII}

Interestingly, ASCII stimuli seem to magnify and uncover a variety of gender differences in facial responses. Women have been found to be significantly more empathetic than men in experimental conditions. For example, women show more empathetic neural responses when making judgements of facial happiness (Rueckert \& Naybar, 2008) and show the effects of empathy for a longer duration than men (Han, Fan, \& Mao, 2008). Women, therefore, may be expressing empathy when they smile in response to :), whereas men, experiencing less empathy, may be expressing amusement at the negative expression :(, just as both genders of participant did when viewing the elicited, and therefore somewhat amusing, photographs of angry faces.

Women have also been found to be more susceptible to affective priming (priming positive or negative affect through an emotionally charged prime) with positive than with negative faces (Donges et al., 2012). This suggests that females are more affected by smiles than frowns, corroborating their increased response to :) versus :(. The same study also found that women were more susceptible to affective priming with smiling faces than were men. Again this corresponds to the findings of the present study, insofar as women are more reactive to :) and less reactive to :( than are men. Arguably then, women are more emotionally affected by :) than men, which may explain women's greater use of emoticons, as found by Baron (2004) and Wolf (2000).

Though lacking explicit emotional content, the ASCII distractors also revealed gendered effects. Many participants mentioned trying to "figure out" the random ASCII strings. Thus, differences in problem solving may be at play. Lowrie and Diezmann (2011) found that males outperform females on graphical problem solving tasks. This suggests that regardless of female participants' problem solving skills, the notion of women as less 
effective problem solvers, as promoted by researchers such as Lowrie and Diezmann (2011), may lead to greater stress for women socialized to believe they are less proficient in the task at hand, thus driving negative affect. In contrast, the males who had an easier time coming to a solution, or at least expected to, may have experienced less frustration and more enjoyment, given perceived male competence in such problem solving.

Use of technology has also been found to be strongly gendered (e.g. Joiner et al., 2005; Cooper, 2006). Indeed, the present study's finding that only $20 \%$ of female participants owned a smartphone, compared to $80 \%$ of male participants, is in line with earlier studies that show men are overall more likely to own and engage with technology (e.g. Cooper, 2006; Hartmann \& Klimt, 2006). Males' increased exposure to such technology, combined with stereotypes of men as more computer literate, have, according to Cooper (2006), created technological anxiety in women. Whether this technological anxiety is real or not, less familiarity with technology, such as smart phones, may result in female participants reacting to meaningless technological symbols with confusion, consternation, and negative facial expression.

\section{Limitations and Future Research}

As a pilot study, this research was limited by a small sample size drawn from a relatively small pool of potential participants. The research was also limited by time factors, which precluded a full process of piloting experimental materials to prevent the humour responses to angry faces and the intense response to the photograph of the seagull. Ideally future research would use natural, rather than elicited, emotional faces and more universally neutral distractor photos.

Given the limitations of the present study, there is significant room left for future exploration of facial mimicry in response to emoticons. Electromyography or high-speed film would allow more fine-grained analysis and would be more likely to catch the rapid changes common to subconscious processes such as facial mimicry. A larger sample size would also allow for more generalizable conclusions across the population as a whole.

Finally, given Yuasa, Saito, and Mukawa's (2011) findings that graphic emoticons cause more activation in the face processing regions of the brain, it would be worthwhile to explore the facial mimicry that results from viewing graphic emoticons such as those supplied by IM platforms, such as Facebook. It would also be interesting to explore reactions to animated 
emoticons in order to investigate whether or not they instigate more responses than static emoticons, as Sato and Yoshikawa (2007) found with dynamic faces vis-à-vis static photos of facial expression.

\section{Conclusion}

In the current research, the degree of similarity or difference between facial expressions and emoticons in their ability to elicit facial mimicry was preliminarily explored. Emoticons were found to elicit mimicry at a higher rate than neutral controls, but at a significantly lower rate than photographs of faces. Gender effects were also found in response to both ASCII emoticons and random strings of ASCII, which offers tantalizing suggestions as to the gendered experience of CMC. This research, though still fairly preliminary, suggests an intriguing line of inquiry into technology, CMC, and gender, which may lead to an enhanced understanding of emotional and non-verbal communications in CMC.

\section{References}

Baron, N. S. (2004). See you online: Gender issues in college student use of instant messaging. Journal of Language and Social Psychology, 23(4), 397-423. doi:10.1177/0261927X04269585. Retrieved from http://jls.sagepub.com.ezproxy.library.uvic.ca/content/23/4/397.full.pdf + html

Buck, R., Savin, V., Miller, R., \& Gaul, W. (1972). Communication of affect through facial expressions in humans. Journal of Personality and Social Psychology, 23, 362-371. doi:10.1037/h0033171. Retrieved from

http://web.ebscohost.com.ezproxy.library.uvic.ca/ehost/detail?sid=de71 2a98-d7c5-4c16-9157-

$3770391 \mathrm{f} 7 \mathrm{fa} \% 40$ sessionmgr $15 \&$ vid=1\&hid=10\&bdata=JnNpdGU9Z Whvc3QtbG12ZSZzY29wZT1zaXRl\#db=pdh\&AN=1973-02397-001

Cacioppo, J.T., \& Petty, R.E. (1981). Electromyograms as measures of extent and affectivity of information processing. American Psychologist, 36, 441-456. doi:10.1037/0003-066X.36.5.441. Retrieved from

http://web.ebscohost.com.ezproxy.library.uvic.ca/ehost/detail?sid=9deb $166 a-c b 7 f-477 a-9 e 2 f-$

46e8afbe556b\%40sessionmgr10\&vid=1\&hid=10\&bdata=JnNpdGU9Z

Whvc3QtbG12ZSZz Y29wZT1zaXRl\#db=pdh\&AN=1982-00677-001 Chaminade, T., Zecca, M., Blakemore, S., Takanishi, A., Frith, C. D., Micera, S., Dario, P., Rizzolatti, G., Gallese, V., \& Umilta, M. A. 
(2010). Brain response to a humanoid robot in areas implicated in the perception of human emotional gestures. PLoS ONE, 5(7), 1-12. doi:10.1371/journal.pone.0011577. Retrieved from http://www.ncbi.nlm.nih.gov/pmc/articles/PMC2908128/?tool=pmcentr ez\&rendertype $=$ abstract

Cooper, J. (2006). The digital divide: The special case of gender. Journal of Computer Assisted Learning, 22, 320-334. doi:10.1111/j.13652729.2006.00185.x. Retrieved from http://web.ebscohost.com.ezproxy.library.uvic.ca/ehost/detail?sid=b9af c7c4-937b-4cb5-8e7a-

8a248152c927\%40sessionmgr4\&vid=1\&hid=10\&bdata=JnNpdGU9Z Whvc3QtbG12ZSZzY29wZT1zaXRl\#db=tfh\&AN=22207651

Danet, B., Ruedenberg-Wright, L., \& Rosenbaum-Tamari, Y. (1997). “HMMM ... WHERE'S THAT SMOKE COMING FROM?” Writing, play and performance on Internet Relay Chat. Journal of ComputerMediated Communication, 2 (4). Retrieved from http://jcmc.indiana.edu/vol2/issue4/danet.html

Derks, D., Bos, A. E. R., \& Grumbkow, J. V. (2004). Emoticons and social interaction on the Internet: The importance of social context. Computer in Human Behaviour, 23, 842-849. doi:10.1016/j.chb.2004.11.013. Retrieved from http://www.sciencedirect.com.ezproxy.library.uvic.ca/science/article/pi i/S0747563204002079

Derks, D., Bos, A. E. R., \& Grumbkow, J. V. (2008a). Emoticons in computer-mediated communication: Social motives and social context. CyberPsychology \& Behaviour, 11(1), 99-101. doi:10.1089/cpb.2007.9926. Retrieved from http://online.liebertpub.

Derks, D., Fischer, A.H., \& Bos, A.E.R, (2008b). The role of emotion in computer-mediated communication: A review. Computers in Human Behaviour 24, 766-785. doi:10.1016/j.chb.2007.04.004. Retrieved from http://www.sciencedirect.com.ezproxy.library.uvic.ca/science/article/pi i/S0747563207000866

Dimberg, U., \& Lundquist, L. (1990). Gender differences in facial reaction to facial expressions. Biological Psychology, 30, 151-159. Retrieved from

http://www.sciencedirect.com.ezproxy.library.uvic.ca/science/article/pi i/030105119090024Q

Dimberg, U., Thunberg, M., \& Elmehed, K. (2000). Unconscious facial reactions to emotional facial expressions. Psychological Science, 11(1), 
86-89. Retrieved from

http://www.jstor.org.ezproxy.library.uvic.ca/stable/40063502

Doherty, R. W., Orimoto, L., Singelis, T. M., Hatfield, E., \& Hebb, J. (1995). Emotional contagion: Gender and occupational differences. Psychology of Women Quarterly, 19, 355-371. doi:10.1111/j.14716402.1995.tb00080.x Retrieved from http://onlinelibrary.wiley.com.ezproxy.library.uvic.ca/doi/10.1111/j.14 71 -

6402.1995.tb00080.x/abstract;jsessionid=E3A58B3E63A3ECE768D17 C0EFF25B02D.d03t02

Donges, U., Kersting, A., \& Suslow, T. (2012). Women's greater ability to perceive happy facial emotion automatically: Gender differences in affective priming. PLOS ONE, 7(7), 1-5.

doi:10.1371/journal.pone.0041745. Retrieved from http://www.ncbi.nlm.nih.gov/pmc/articles/PMC3402412/?tool=pmcentr ez\&rendertype $=$ abstract

Dresner, E., \& Herring, S. C. (2010). Functions of the nonverbal in CMC: emotions and illocutionary force. Communication Theory, 20, 249268. doi:10.1111/j.1468-2885.2010.01362.x. Retrieved from http://onlinelibrary.wiley.com.ezproxy.library.uvic.ca/doi/10.1111/j.14 68-2885.2010.01362.x/abstract

Ebner, N. C., Riediger, M., \& Lindenberger, U. (2010). FACES-A database of facial expressions in young, middle-aged, and older women and men: Development and validation. Behavior Research Methods, 42, 351-362. doi:10.3758/BRM.42.1.351.Retrieved from http://pubman.mpdl.mpg.de/pubman/item/escidoc:95169:19/

Ekman, P., \& Friesen, W. V. (1978). Facial action coding system. Palo Alto, CA: Consulting Psychologist. Online reference available from http://www.cs.cmu.edu/ face/facs.htm

Fahlman, S. E. (n.d.). Original Bboard Thread in which :-) was proposed. Retrieved from http://www.cs.cmu.edu/ sef/Orig-Smiley.htm

Garrison, A., Remley, D., Thomas, P., \& Wierszewski, E. (2011).

Conventional faces: Emoticons in instant messaging discourse.

Computers and Composition, 28, 112-115.

doi:10.1016/j.compcom.2011.04.001. Retrieved from

http://www.sciencedirect.com.ezproxy.library.uvic.ca/science/article/pi i/S8755461511000223

Han, S., Fan, Y., \& Mao, L. (2008). Gender difference in empathy for pain: An electrophysiological investigation. Brain Research, 1196, 85-93. 
doi:10.1016/ j.bainres.2007.12.062 or

http://www.sciencedirect.com.ezproxy.library.uvic.ca/science/article/pi i/S0006899307030284

Hartmann, T. \& Klimmt, C. (2006). Gender and Computer Games:

Exploring Females' Dislikes. Journal of Computer-Mediated

Communication, 11, 910-931. doi:10.1111/j.1083-6101.2006.00301.x.

Retrieved from

http://onlinelibrary.wiley.com.ezproxy.library.uvic.ca/doi/10.1111/j.10 83-6101.2006.00301.x/abstract

Hatfield, E., Cacioppo, J., \& Rapson, R. (1994). Emotional contagion. New York: Cambridge University Press.

Hess, U., Philippot, P., \& Blairy, S. (1999). Mimicry: Facts and Wction. In P. Philippot, R. Feldman, \& E. Coats (Eds.), The social context of nonverbal behavior (213-241). New York: Cambridge University Press.

Hobson, R. P., Ouston, J., \& Lee, A. (1988). What's in a face? The case of autism. British Journal of Psychology, 79, 441-453

Huang, A.H., Yen, D.C., \& Zhang, X. (2008). Exploring the potential effects of emoticons. Information \& Management 45, 466-473. doi:10.1016/j.im.2008.07.001. Retrieved from http://www.sciencedirect.com.ezproxy.library.uvic.ca/science/article/pi i/S037872060800089X

Joiner R., Gavin J., Brosnan M., Crook C., Duffield J., Durndell A., Maras P., Miller J., Scott A.J. \& Lovatt P. (2005) Gender, internet identification, and internet anxiety: correlates of internet use. Cyberpsychology and Behavior 8, 371-378. doi:10.1089/cpb.2005.8.371. Retrieved from http://online.liebertpub.com/doi/abs/10.1089/cpb.2005.8.371

Lo, S. (2008). The nonverbal communication functions of emoticons in computer-mediated communication. CyberPsychology \& Behaviour, 11(5), 595-597. doi:10.1089/cpb.2007.0132. Retrieved from http://online.liebertpub.com/doi/abs/10.1089/cpb.2007.0132

Lowrie, T. \& Diezmann, C. M. (2011). Solving graphics tasks: Gender differences inmiddle-school students. Learning and Instruction, 21, 109-125. doi:10.1016/j.learninstruc.2009.11.005. Retrieved from http://www.sciencedirect.com.ezproxy.library.uvic.ca/science/article/pi i/S095947520900125X

Luor, T., Wu, L., Lu, H., \& Tao, Y. (2010). The effect of emoticons in simplex and complex task-oriented communication: An empirical 
study of instant messaging. Computers in Human Behaviour, 26, 889895. doi:10.1016/j.chb.2010.02.003. Retrieved from http://www.sciencedirect.com.ezproxy.library.uvic.ca/science/article/pi i/S0747563210000191

Provine, R.R., Spencer, R.J., \& Mandell, D.L. (2007). Emotional expression online: Emoticons punctuate website text messages. Journal of Language and Social Psychology, 26(3), 299-307. doi:10.1177/0261927X06303481. Retrieved from http://jls.sagepub.com.ezproxy.library.uvic.ca/content/26/3/299.full.pdf + html

Rezabek, L. L., \& Cochenour, J. J. (1998). Visual cues in computermediated communication: Supplementing text with emoticons. Journal of Visual Literacy, 18(2), 201-215.

Rivera, K., Cooke, N. J., \& Bauhs, J. A. (1996). The effects of emotional icons on remote communication. Computer Human Interaction Interactive Poster, 96, 99-100. doi:10.1145/257089.257180. Retrieved from http://dl.acm.org.ezproxy.library. uvic.ca/citation.cfm?id=257180

Rueckert, L. \& Naybar, N. (2008). Gender differences in empathy: The role of the right hemisphere. Brain and Cognition, 67, 162-167.

doi:10.1016/j.bandc.2008.01.002.Retrieved from http://www.sciencedirect.com.ezproxy.library.uvic.ca/science/article/pi i/S0278262608000055

Sato, W. \& Yoshikawa, S. (2007). Spontaneous facial mimicry in response to dynamic facial expressions. Cognition, 104, 1-18. doi:10.1016/j.cognition.2006.05.001.Retrieved from http://www.sciencedirect.com.ezproxy.library.uvic.ca/science/article/pi i/S001002770600120X

Suki, N.M. \& Suki, N.M. (2007), Mobile phone usage for m-learning: comparing heavy and light mobile phone users. Campus Wide Information System, 24(5), 355-65. doi:10.1108/10650740710835779. Retrieved from http://www.emeraldinsight.com.ezproxy.library.uvic.ca/journals.htm?ar ticleid $=1634451 \&$ show $=$ abstract

Thompson, P. A., \& Foulger, D. A. (1996). Effects of pictographs and quoting on flaming in electronic mail. Computers in Human Behavior, 12, 225-243. Retrieved from http://www.sciencedirect.com.ezproxy.library.uvic.ca/science/article/pi i/0747563296000040

Walther, J. B., \& D’Addario, K. P. (2001). The impacts of emoticons on 
message interpretation in computer-mediated communication. Social Science Computer Review, 19(3), 324-347.

doi:10.1177/089443930101900307. Retrieved from http://ssc.sagepub.com.ezproxy.library.uvic.ca/content/19/3/324.full.pd $\mathrm{f}+\mathrm{html}$

Wild, B., Erb, M., \& Bartels, M. (2001). Are emotions contagious? Evoked emotions while viewing emotionally expressive faces: quality, quantity, time course and gender differences. Psychiatry Research, 102, 109124. Retrieved from

http://www.sciencedirect.com.ezproxy.library.uvic.ca/science/article/pi i/S0165178101002256

Wolf, A. (2000). Emotional expression online: Gender difference in emoticon use. CyberPsychology \& Behaviour, 3(5), 827-833. doi:10.1089/10949310050191809. Retrieved from http://online.liebertpub.com/doi/abs/10.1089/10949310050191809

Yuasa, M., Saito, K., \& Mukawa, N. (2011). Brain activity associated with graphic emoticons. The effect of abstract faces in communication over a computer network. Electrical Engineering in Japan, 177(3), 36-44. doi:10.1002/eej.21162. Retrieved from http://web.ebscohost.com.ezproxy.library.uvic.ca/ehost/detail?sid=39a2 cb87-899a-4cac-8271-f7814954e392\%40sessionmgr14\&vid=1\&hid= 10\&bdata=JnNpdGU9ZWhvc3QtbG12ZSZzY29wZT1zaXRl\#db=a9h\& $\mathrm{AN}=62836996$

Yuasa, M., Saito, K., \& Mukawa, N. (2011b). Brain activity when reading sentences and emoticons: An fMRI study of verbal and nonverbal communication. Electronics and Communications in Japan, 94(5), 1724. doi:10.1002/ecj.10311. Retrieved from http://web.ebscohost.com.ezproxy.library.uvic.ca/ehost/detail?sid=4f 88 ec41-614d-40d0-9d62-

930a5392bf80\%40sessionmgr 13\&vid=1\&hid=10\&bdata=JnNpdGU9Z Whvc3QtbGl2ZSZzY29wZT1zaXRl\#db=a9h\&AN=60154504

\section{Contact Information}

Brittney O'Neill, from the Department of Linguistics, can be reached at Brittney.on@gmail.com.

\section{Acknowledgements}

First and foremost I would like to thank Dr. Alexandra D'Arcy for always encouraging my research and exploration in the emerging field of CMC 
The Arbutus Review Vol. 4, No. 1 (2013)

research in linguistics, for dynamic seminars that inspired my work, and for her help editing and presenting this study. I would also like to thank the Learning and Teaching Centre and The Arbutus Review for giving me the opportunity to publish and share my research. Finally, I must thank my techno-savvy peers whose engagement with CMC has made my work both meaningful and possible. 